\title{
Characterization of Free and Porous Silicon-Encapsulated Superparamagnetic Iron Oxide Nanoparticles as Platforms for the Development of Theranostic Vaccines
}

\author{
Charles M. Lundquist ${ }^{1}$, Christopher Loo ${ }^{2, \dagger}$, Ismail M. Meraz ${ }^{2, \dagger}$, Jorge De La Cerda ${ }^{3}$, \\ Xuewu Liu ${ }^{2}$ and Rita E. Serda ${ }^{2, *}$
}

1 Nanomedicine and Biomedical Engineering, The University of Texas School of Medicine, Houston, TX 77030, USA; E-Mail: CharlesLundquist@gmail.com

2 Department of Nanomedicine, Houston Methodist Research Institute, 6670 Bertner Ave, Houston, TX 77030, USA; E-Mails: ch11357@gmail.com (C.L.); immeraz@houstonmethodist.org (I.M.M.); xliu@houstonmethodist.org (X.L.)

3 Small Animal Imaging Facility, University of Texas MD Anderson Cancer Center, 1515 Holcombe Blvd., Houston, TX 77030, USA; E-Mail: Jorge.DeLaCerda@mdanderson.org

$\dagger$ These authors contributed equally to this work.

* Author to whom correspondence should be addressed; E-Mail: ritaserda@gmail.com or rita.serda@bcm.edu; Tel.: +1-713-798-3242.

Received: 2 December 2013; in revised form: 27 January 2014 / Accepted: 27 January 2014 /

Published: 20 February 2014

\begin{abstract}
Tracking vaccine components from the site of injection to their destination in lymphatic tissue, and simultaneously monitoring immune effects, sheds light on the influence of vaccine components on particle and immune cell trafficking and therapeutic efficacy. In this study, we create a hybrid particle vaccine platform comprised of porous silicon (pSi) and superparamagnetic iron oxide nanoparticles (SPIONs). The impact of nanoparticle size and mode of presentation on magnetic resonance contrast enhancement are examined. SPION-enhanced relaxivity increased as the core diameter of the nanoparticle increased, while encapsulation of SPIONs within a pSi matrix had only minor effects on $\mathrm{T}_{2}$ and no significant effect on $\mathrm{T}_{2} *$ relaxation. Following intravenous injection of single and hybrid particles, there was an increase in negative contrast in the spleen, with changes in contrast being slightly greater for free compared to silicon encapsulated SPIONs. Incubation of bone marrow-derived dendritic cells (BMDC) with pSi microparticles loaded with SPIONs, SIINFEKL peptide, and lipopolysaccharide stimulated
\end{abstract}


immune cell interactions and interferon gamma production in OT-1 TCR transgenic CD8 ${ }^{+}$ $\mathrm{T}$ cells. Overall, the hybrid particle platform enabled presentation of a complex payload that was traceable, stimulated functional $\mathrm{T}$ cell and BMDC interactions, and resolved in cellular activation of $\mathrm{T}$ cells in response to a specific antigen.

Keywords: porous silicon; iron oxide; magnetic resonance; antigen; adjuvant; vaccine

\section{Introduction}

Cellular uptake of microbes by dendritic cells (DC) is accompanied by engagement of pattern recognition receptors $[1,2]$. Activation of these receptors induces phagocytosis and expression of genes that cause maturation of the cell and activation of anti-microbial events, thereby inducing innate immunity. Particles carrying pathogen-associated molecular patterns, e.g., lipopolysaccharide (LPS), similarly induce phagocytosis and activate antigen presenting cells (APC). We previously demonstrated that DC incubated with porous silicon (pSi) particles presenting LPS and antigen (i.e., ovalbumin peptide SIINFEKL) are actively engaged by T cells obtained from C57BL/6-Tg(TcraTcrb) (a.k.a. OT-1) mice expressing a transgenic TCR for recognition of major histocompatibility complex (MHC) class I-presented antigen. The stimulated DC have enhanced migration to the draining lymph node and elevated expression of MHC and costimulatory molecules, as well as increased secretion of proinflammatory cytokines. While these early studies relied on ex vivo modification of APC with fluorescent tracers, particle-based vaccines that incorporate contrast agents can be used experimentally or clinically for noninvasive detection by magnetic resonance imaging (MRI) to track migration of particles, or their cell-based carriers, to lymphatic tissue for modulation of immune responses.

Contrast in MR images is due to differences in signal relaxation rates that are unique to the physical and chemical characteristics of biological tissues [3]. Return to the equilibrium occupancy of spins following excitation is referred to as longitudinal relaxation, and is characterized by an exponential time constant generally referred to as $T_{1}$. Attenuation of the excited signal due to the dephasing of spins is known as transverse relaxation, which is referred to as $T_{2}$. Inhomogeneities in the magnetic field that are not compensated for through the use of a spin-echo pulse sequences lead to shorter transverse relaxation time constants, denoted as $\mathrm{T}_{2} *$ to differentiate intrinsic tissue relaxation from that induced by magnetic field inhomogeneities. Exogenous contrast agents act to reduce these time constants; for example, an agent that reduces $\mathrm{T}_{1}$ increases signal intensity by accelerating the return to equilibrium between excitations, while an agent that reduces $\mathrm{T}_{2}$ or $\mathrm{T}_{2} *$ causes the signal to attenuate more quickly after excitation, leading to negative (dark) contrast $[4,5]$. The relaxation time $\left(\mathrm{T}_{2}, \mathrm{~T}_{2}{ }^{*}\right)$ and concentration of contrast agent are related by the following equations [6]:

$$
\begin{gathered}
R_{1,2}=R_{1,2}^{0}+r_{1,2} \cdot C \\
R_{1,2}^{0}=\frac{1}{T_{1,2}^{0}}, R_{1,2}=\frac{1}{T_{1,2}}
\end{gathered}
$$

where $T_{1,2}$ is the relaxation time at a given concentration of contrast agent, $T_{1,2}^{0}$ is the relaxation time of the medium with contrast agent removed, $C$ is the concentration of contrast agent, and $r_{1,2}$ is the 
concentration-independent relaxivity of the contrast agent under study. The term $R_{1,2}$ in the above equation is referred to as the relaxation rate.

Superparamagnetic iron oxide nanoparticles (SPIONs) shorten $\mathrm{T}_{2}$ and $\mathrm{T}_{2}{ }^{*}$ due to their large magnetic moments and the large magnetic field gradients that surround them [7]. The ability of SPIONs to enhance contrast depends on their size, surface properties, aggregation and compartmentalization [8-10]. For homogeneously dispersed small particles, the motional averaging regime (MAR theory) predicts that transverse relaxivities, $r_{2}$ and $r_{2}{ }^{*}$, increase with increasing core size [11]. That is, the ability of SPIONs to act as contrast agents to lower the $T_{2}$ relaxation time of tissues is enhanced by increasing the particle core size due to increased magnetic susceptibility. It has been shown that increasing the core size results in a higher induced magnetization at saturation and thus a higher magnetic susceptibility, calculated as $M=\chi \bullet H$, where $\mathrm{M}$ is the induced magnetization, $H$ is the field strength of the magnet, and $\chi$ is the suseptibility of the magnetic particle $[11,12]$. Above a certain size, further increases in core size fail to enhance relaxation rates based on the existence of strong dipolar fields surrounding the particle, limiting the impact of water diffusion and leading to a plateau in relaxation rate. For smaller particles, $r_{2}$ and $r_{2} *$ should be nearly equal based on dependence on diffusion effects, however, for larger particles, the static dephasing regime (SDR theory) predicts that $\mathrm{R}_{2}$ * increases with increasing local magnetic dose, meaning that particle aggregation leads to increases in $\mathrm{R}_{2}{ }^{*}$ [8]. In this study, we compare transverse relaxivities of SPIONs with increasing particle core size ranging from 5 to $30 \mathrm{~nm}$; and we examine the impact of SPION confinement within a pSi matrix on magnetic properties [13]. This data was presented in an abstract in the Proceedings of the ASME 2nd Global Congress on NanoEngineering for Medicine and Biology [13].

Size and aspect ratio of particles are important properties that impact particle biodistribution, cellular interactions, and cellular internalization [14-16]. With respect to subcutaneous inoculation, particles traffic to lymphatic tissue (i.e., lymph nodes) in a size-dependent manner, with large particles being engulfed by peripheral APCs at the site of injection, and small nanoparticles being internalized by resident APCs following cell-free trafficking [17]. In this study, we explore accumulation of free and pSi-encapsulated SPIONs in the spleen following intravenous injection to study the impact of nanoparticle and microparticle trafficking to lymphatic tissue via the vascular system. We further compare $\mathrm{T}$ cell immunity stimulated by pSi microparticles presented as single verses hybrid particle complexes.

\section{Experimental Section}

\subsection{Materials}

SPIONs were purchased from Ocean Nanotech, LLC (Springdale, AR, USA). The iron oxide nanocrystals had an amphiphilic polymer coating containing terminal amine groups attached to polyethylene glycol linkers, or carboxylic acid moieties. C57BL/6 and C57BL/6-Tg(TcraTcrb) (OT-1) mice were obtained from Charles River Laboratories, Inc. (Wilmington, MA, USA) and The Jackson Laboratory (Bar Harbor, ME, USA), respectively. 


\subsection{Fabrication of pSi Microparticles}

$1 \mu \mathrm{m}$ (diameter) $\times 400 \mathrm{~nm}$ (thickness) discoidal $\mathrm{pSi}$ microparticles were fabricated in the Microelectronics Research Center at The University of Texas at Austin by combination of electrochemical etching and standard photolithography. Using heavily doped p++ type (100) silicon wafers with resistivity of $0.005 \mathrm{ohm}-\mathrm{cm}$ (Silicon Quest, Inc., Santa Clara, CA, USA) as the silicon source and $1 \mathrm{HF}$ (49\%): 3 ethanol solution as etchant, the anodic etching process started with applying a $2.3 \mathrm{~mA} / \mathrm{cm}^{2}$ current for $20 \mathrm{~s}$ to form a low porosity mechanical layer, then the current was ramped to $14 \mathrm{~mA} / \mathrm{cm}^{2}$ in a time course of $15 \mathrm{~s}$, and kept at $14 \mathrm{~mA} / \mathrm{cm}^{2}$ for $45 \mathrm{~s}$ to form the porous layer with $60 \mathrm{~nm}$ average pores. A current of $76 \mathrm{~mA} / \mathrm{cm}^{2}$ was applied for $6 \mathrm{~s}$ to form the high porosity release layer. Following the formation of porous film, a $40 \mathrm{~nm} \mathrm{SiO}$ layer was deposited by Low Pressure Chemical Vapor Deposition at $400{ }^{\circ} \mathrm{C}$. Standard photolithography was then used to pattern an array of $1 \mu \mathrm{m}$ circles over the $\mathrm{SiO}_{2}$ capped porous film using a contact aligner (K.Suss MA6 mask aligner) and NR9-500P photoresist (Futurrex, Franklin, NJ, USA). The pattern was transferred into the porous film by Reactive Ion Etch in $\mathrm{CF}_{4}$ plasma (Plasmatherm BatchTop, 15 sccm CF4, 100 mTorr, $200 \mathrm{~W}$ RF). The capping $\mathrm{SiO}_{2}$ layer was removed in $49 \% \mathrm{HF}$, and the microparticles were released from the substrate in isopropanol by sonication.

\subsection{Surface Modification of pSi Microparticles}

pSi microparticles were oxidized with piranha solution ( 1 volume $\mathrm{H}_{2} \mathrm{O}_{2}$ and 2 volumes of $\mathrm{H}_{2} \mathrm{SO}_{4}$ ) with heating to $110-120{ }^{\circ} \mathrm{C}$ for $2 \mathrm{~h}$ as previously described [18]. Oxidized pSi microparticles were washed in IPA, and then suspended in IPA containing 0.5\% $(v / v)$ APTES (Sigma-Aldrich, St. Louis, MO, USA) for $0.5-2 \mathrm{~h}$ at $35^{\circ} \mathrm{C}$ and $1300 \mathrm{rpm}$. The APTES-modified pSi microparticles were washed in IPA and dried in a desiccator. Volumetric particle size, size distribution and count were obtained using a Multisizer 4 Coulter ${ }^{\circledR}$ Particle Counter (Beckman Coulter, Fullerton, CA, USA). The morphology of the particles was verified by scanning electron microscopy (SEM, FEI, Hillsboro, OR, USA).

\subsection{MRI Phantoms}

MR phantoms were prepared in thin wall NMR tubes with $10 \mathrm{~mm}$ outer diameters (Wilmad Labglass, Vineland, NJ, USA). Samples of free SPIONs with core sizes of 5, 10, 20, and $30 \mathrm{~nm}$ were prepared by adding a $0.005,0.01,0.03$, and $0.05 \mathrm{mg} \mathrm{Fe} / \mathrm{mL}$ to a $1 \%$ agarose suspension to create unique sample tubes for each core size. Iron content was verified using a Prussian blue assay as described later. Sample sets of 4-5 phantoms, including a 1\% agarose only control, were moved into a specially-machined tube holder which was placed into a $300 \mathrm{~mL}$ cylindrical polypropylene tube. The tube was then filled with relaxed water (doped with $0.1 \%$ Magnevist $v / v$ ) to reduce proximity to and interference from air interfaces, capped, sealed, and imaged. MR imaging of phantoms was carried out in an actively-shielded 7 Tesla Biospec USR70/30 (Bruker Biospin MRI, Billerica, MA, USA) small animal MRI system equipped with a 30-cm bore, imaging gradients with a $6-\mathrm{cm}$ free bore, and a linear ${ }^{1} \mathrm{H}$ birdcage-style volume resonator with $35 \mathrm{~mm}$ inner diameter. A three-plane, $\mathrm{T}_{2}$-weighted fast spin-echo sequence $(\mathrm{TE}=50 \mathrm{~ms}, \mathrm{TR}=2000 \mathrm{~ms}$, ETL $=8$ ) was used to confirm sample placement. 
Transverse relaxation time constants $\left(\mathrm{T}_{2}{ }^{*}\right)$ were measured using a multi-echo gradient-echo sequence (minimum TE $=1.5 \mathrm{~ms}$, echo spacing $3.25 \mathrm{~ms}, 24$ echoes, $\mathrm{TR}=4,000 \mathrm{~ms}, 30$ excitation).

\subsection{Loading SPIONs into pSi Microparticles}

Experiments comparing relaxivity values for free verses pSi-encapsulated $30 \mathrm{~nm}$ SPIONs were performed by loading $1 \times 10^{8} \mathrm{pSi}$ microparticles with serial dilutions of $5,2.5,1.75 \mathrm{mg} \mathrm{Fe} / \mathrm{mL}$. Loading was accomplished by means of capillary action by adding SPION suspensions to dry pSi microparticles, briefly sonicating, and incubating for $15 \mathrm{~min}$ at room temperature. The microparticles were then washed with $50 \mu \mathrm{L}$ of DI water and centrifuged at $5000 \times g \times 10 \mathrm{~min}$. The supernatant with excess unloaded SPIONs was pipetted off and the pSi microparticles were desiccated under vacuum. The loading and wash steps were then repeated and the resulting loaded pSi microparticles were suspended in 1\% agarose for imaging. The iron content in the samples was verified using inductively coupled plasma-atomic emission spectroscopy (ICP-AES, Agilent Technologies, Santa Clara, CA, USA) as described below.

\subsection{ICP-AES Analysis of Iron in Phantoms and Tissue Samples}

To verify the iron content of the resected tissues, spleen were dehydrated with ethanol and dried overnight. Samples were weighed and placed into nickel crucibles, which were heated in a $500{ }^{\circ} \mathrm{C}$ oven for several hours. Once fully ashed, tissue remains were collected by washing the crucibles with $1 \%$ spectrosol ${ }^{\mathrm{TM}}$ solution and sonicating, up to a final volume of $5 \mathrm{~mL}$. Samples were centrifuged at $4200 \mathrm{rpm}$ for $10 \mathrm{~min}$ to remove ash aggregates from the solution and $4 \mathrm{~mL}$ of the dissolved sample was moved to a new conical tube. $1 \mathrm{~mL}$ of a $1 \%$ spectrosol solution, plus $50 \mu \mathrm{L}$ of $100 \mathrm{mg} / \mathrm{L}$ yttrium standard solution, was added to each tube and were analyzed using iron standard concentrations of 25 , $75,100,250$, and $500 \mathrm{ppb}$, one blank sample of $1 \%$ spectrosol solution, and one quality control internal standard containing $250 \mathrm{ppb}$ of iron. Samples were analyzed with a Varian Vista AX at a power of $1 \mathrm{~kW}$, plasma flow set to $15 \mathrm{~L} / \mathrm{min}$, auxiliary flow of $1.5 \mathrm{~L} / \mathrm{min}$, and a nebulizer flow of $0.75 \mathrm{~L} / \mathrm{min}$, with 5 replicate readings at $15 \mathrm{~s}$ between each reading. The concentration of iron in agarose phantoms was measured by serial dilution of the phantom contents with a reference range of 25-500 ppb. A final volume of $5 \mathrm{~mL}$ of $1 \%$ spectrosol plus sample solution was used.

\subsection{Prussian Blue Assay for Iron Content}

To verify total iron content of phantoms used for particle size comparisons, $5 \mu \mathrm{L}$ samples of 5,10 , 20, and $30 \mathrm{~nm}$ stock solutions, as well as Ferric iron (III) standards at 1.5, 1, 0.5, 0.1, and $0.05 \mathrm{mg} / \mathrm{mL}$ were incubated with $120 \mu \mathrm{L} 6 \mathrm{~N} \mathrm{HCl}$ for $2 \mathrm{~h}$ at $60{ }^{\circ} \mathrm{C}$ in triplicate. Iron was then oxidized using $0.1 \mathrm{mg} / \mathrm{mL}$ ammonium persulfate (BioRad, Richmond, CA, USA) and the color reaction was initiated by adding $125 \mu \mathrm{L}$ of a $5 \% \mathrm{~K}_{4}\left[\mathrm{Fe}(\mathrm{CN})_{6}\right] \cdot 3 \mathrm{H}_{2} \mathrm{O}$ (Sigma-Aldrich) for $10 \mathrm{~min}$. Following incubation, sample absorbance was determined at $690 \mathrm{~nm}$ using a SPECTRA max M2 plate reader (Molecular Devices, Sunnyvale, CA, USA). A standard curve was then generated using iron III hexahydrate (Sigma-Aldrich) and the iron concentration of SPION preparations was calculated. Cells treated with 
particles for $24 \mathrm{~h}(20 \mathrm{pSi}$ particles/cell or $2 \mu \mathrm{g} / \mathrm{mL} \mathrm{Fe}$ ) were labeled by incubation of cells in acid solution containing potassium ferrocyanide for $30 \mathrm{~min}$ at $37^{\circ} \mathrm{C}$.

\subsection{In Vivo Imaging Experiments}

All animal procedures were performed in accordance with recommendations by the National Institutes of Health in the guide "Care and use of Laboratory Animals." All protocols were reviewed and approved by the Institutional Animal Care and Use Committee at The Methodist Hospital Research Institute (TMHRI), Houston, Texas (Protocol \#AUP-1010-0028 and AUP-0311-0012; OLAW Assurance \#A4555-01) and at the University of Texas MD Anderson Cancer Center. Time-dependent accumulation of SPIONs in the spleen of female nu/nu mice (Charles River, Wilmington, MA, USA) was determined by intravenous injection of $100 \mu \mathrm{g}$ SPIONs (Fe content; $20 \mathrm{~nm}$ core) in $100 \mu \mathrm{L}$ PBS. Spleens were excised from mice at 2 and $24 \mathrm{~h}$, suspended in agarose phantoms, and $\mathrm{T}_{2}$-weighted images were acquired using a 7 Tesla scanner as described previously.

To determine the impact of pSi encapsulation of SPIONs on contrast enhancement in live animals, mice were intravenously injected with PBS or $100 \mu \mathrm{g}$ of $30 \mathrm{~nm}$ SPIONs (free or pSi-encapsulated). $\mathrm{T}_{2}$-weighted images were taken $24 \mathrm{~h}$ post-injection. Signal intensities were determined for 5 regions of interest (mid-section of 5 slices), with normalization against a reference phantom containing $0.01 \mathrm{mg} / \mathrm{mL}$ SPIONs or against the psoas muscle. Spleens were isolated and embedded in paraffin $24 \mathrm{~h}$ after pSi-SPION injections. Tissue sections were labeled with Prussian blue and Nuclear Fast Red as previously described [19].

\subsection{Preparation of Adjuvant Particles}

An aqueous $1 \mathrm{mg} / \mathrm{mL}$ solution of lipopolysaccharide (LPS) from Escherichia coli (400 $\mu \mathrm{g}$; Sigma-Aldrich, St. Louis, MO, USA) was treated with ethyl-dimethylaminopropyl carbodiimide $(270 \mu \mathrm{g})$ to convert carboxyl units to amine-reactive intermediates (final volume $500 \mu \mathrm{L}$ ), and then introduced to APTES-modified pSi microparticles to create stable amide bonds $\left(2 \mathrm{~h}\right.$ at $30{ }^{\circ} \mathrm{C}$ with agitation at $1400 \mathrm{rpm})$, followed by washing. LPS-adsorbed $(1 \mathrm{mg} / \mathrm{mL})$ microparticles $\left(3 \times 10^{8}\right)$, dried in a desicator, were loaded by capillary action as previously described using a solution made by mixing $50 \mu \mathrm{L}$ OVA peptide (SIINFEKL (Genscript, Piscataway, NJ, USA); $10 \mu \mathrm{g} / \mathrm{mL}$ ) with $50 \mu \mathrm{L}(50 \mu \mathrm{g}$ ) amine-modified SPIONs $(20 \mathrm{~nm})$.

\subsection{Intracellular Interferon Assay}

C57BL/6 (Charles River Laboratories, Inc.; Wilmington, MA, USA) BMDC were prepared by culturing bone marrow cells in granulocyte macrophage colony stimulating factor $(20 \mathrm{ng} / \mathrm{mL})$ and interleukin (IL)-4 (100 ng/mL) for 5 days. Splenic T-cells suspensions were prepared from OT-1 mice (The Jackson Laboratory, Bar Harbor, ME, USA) by passing cells through a $70 \mu \mathrm{m}$ cell strainer and enriching $\mathrm{T}$ cells using a Dynal ${ }^{\circledR}$ Mouse $\mathrm{T}$ cell Negative Isolation kit (Invitrogen, Grand Island, NY, USA). BMDC were incubated with microparticles (20 to 1 ratio) for $2 \mathrm{~h}$ followed by $18 \mathrm{~h}$ co-culture with $\mathrm{T}$ cells at a one-to-one ratio $\left(5 \times 10^{5}\right.$ each $)$. Cells were permeabilized with Cytofix/Cytoperm ${ }^{\mathrm{TM}}$ solution and incubated with PE-conjugated anti-interferon gamma (IFN- $\gamma$ ) and FITC-conjugated 
anti-CD8 antibodies (BD Biosciences, Mountain View, CA, USA) for $30 \mathrm{~min}$ at $4{ }^{\circ} \mathrm{C}$. Samples were analyzed using a LSRFortessa ${ }^{\mathrm{TM}}$ Flow Cytometer (BD Biosciences, San Jose, CA, USA) using FACSDIVATM $^{\text {TM }}$ software (BD Biosciences, San Jose, CA, USA) [20]. Statistical analysis was based on a two-tailed, equal variance $t$-test ( $n=3$ per group).

\subsection{Electron Microscopy Imaging of Particles and BMDC}

SPIONs were suspended in water and dried on a formvar 400 mesh grid. Images were acquired using a JEOL 1200 transmission electron microscope (TEM, JEOL, Peabody, MA, USA) at $60 \mathrm{kV}$ with digital images collected using a $1 \mathrm{k} \times 1 \mathrm{k}$ Gatan BioScan camera Model 792 .

BMDC were cultured on poly-l-lysine glass slides with LPS-bound pSi microparticles (1:20 ratio) in the presence of $10 \mu \mathrm{g} / \mathrm{mL}$ SIINFEKL peptide for $3 \mathrm{~h}$ at $37^{\circ} \mathrm{C}$. OT-1 splenic T cells were introduced at a ratio of 2:1 (BMDC:T) and cells were incubated for an additional hour. Following fixation in 2\% glutaraldehyde in $0.1 \mathrm{M}$ cacodylate buffer, $\mathrm{pH} 7.4$, cells were incubated in a mixture of osmium tetroxide $\left(\mathrm{OsO}_{4}\right)$ and $1 \%$ potassium ferrocyanate in $0.1 \mathrm{M}$ cacodylate buffer for $30 \mathrm{~min}$ at $48{ }^{\circ} \mathrm{C}$. Cells were then dehydrated and embedded with a mixture of epon and araldite. Ultrathin sections were counter-stained with uranyl acetate and imaged using a JEOL 1210 transmission electron microscope equipped with an AMT Imaging System. Gamma adjustments were made to the micrographs to enhance image contrast and brightness.

For surface topography imaging by scanning electron microscopy (SEM), BMDC were plated in 24 well plates containing $5 \times 7 \mathrm{~mm}$ silicon chip specimen supports (Ted Pella, Inc., Redding, CA, USA) at $1 \times 10^{5}$ cells per well. The next day, cells were incubated with pSi microparticles for $3 \mathrm{~h}$ at $37{ }^{\circ} \mathrm{C}$ (1:10; cell:microparticle ratio). BMDC were either fixed and dehydrated as previously described [18,21] for SEM imaging or further incubated with OT-1 $\mathrm{T}$ cells for an additional hour then processed for imaging. Cells were sputter-coated with a $4 \mathrm{~nm}$ layer of platinum/palladium (80:20) using a Cressington Sputter Coater 208 HR (Ted Pella, Inc., Redding, CA, USA). SEM images were acquired under high vacuum, at $10 \mathrm{kV}$, spot size 3.0, using a Nova ${ }^{\mathrm{TM}}$ NanoSEM (FEI Company, Hillsboro, OR, USA). Images were pseudo-colored and gamma levels were adjusted to enhance image contrast and brightness.

\subsection{Statistical Analysis}

Relaxivity data is expressed as the slope of the relaxation rate $v s$. concentration. The slope was calculated by best fit linear regression analysis using the least squares method. $95 \%$ confidence intervals were generated using the standard error of the slope $\left(\mathrm{SE}_{\text {slope }}\right)$, given by the following equation:

$$
\mathrm{SE}_{\text {slope }}=\operatorname{sqrt}\left[\Sigma\left(y_{i}-\hat{y}_{i}\right)^{2} /(n-2)\right] / \operatorname{sqrt}\left[\Sigma\left(x_{i}-x\right)^{2}\right]
$$

where $y_{i}$ is the value of relaxation rate for instance $i, \hat{y}_{i}$ is estimated value of the relaxation rate for observation $i, x_{i}$ is the observed value of the concentration for observation $i, x$ is the mean of the concentration, and $n$ is the number of data points $(n=5)$. The $95 \%$ confidence interval was then calculated using the formula

$$
\mathrm{CI}= \pm \mathrm{SE}_{\text {slope }} \times 1.96
$$


Regression analysis was done using a single set of relaxation rate measurements $v$ s. concentration for each of the free or encapsulated SPION particle preparations analyzed. Significance was determined with non-overlapping confidence intervals.

\section{Results}

\subsection{Hybrid Particles}

TEM images of SPIONs, with core sizes ranging from 5 to $30 \mathrm{~nm}$, are presented in Figure 1a. The particles are uniform in size and distribution. SEM images confirm that pSi microparticles are discoidal in shape with dimensions of $1000 \times 400 \mathrm{~nm}$ (Figure 1b). The porosity of the microparticles is $70 \%-80 \%$, with each microparticle having a volume of $0.2 \mu \mathrm{m}^{3}$, with an average surface pore diameter of $50 \mathrm{~nm}$. Abundant loading of SPIONs by capillary action into the pSi matrix is shown in Figure $1 \mathrm{~b}$.

Figure 1. Electron micrographs of single and hybrid particles. (a) TEM images of superparamagnetic iron oxide nanoparticles (SPIONs) with core sizes of 5, 10, 20, and $30 \mathrm{~nm}$ on $400 \mathrm{mesh}$ formvar carbon grids, imaged at 200,000× direct magnification (bars $=100 \mathrm{~nm}$ ); (b) SEM images of discoidal porous silicon (pSi) microparticles, unloaded (left) or loaded with $30 \mathrm{~nm}$ SPIONs (right, with image periphery pseudo-colored black).

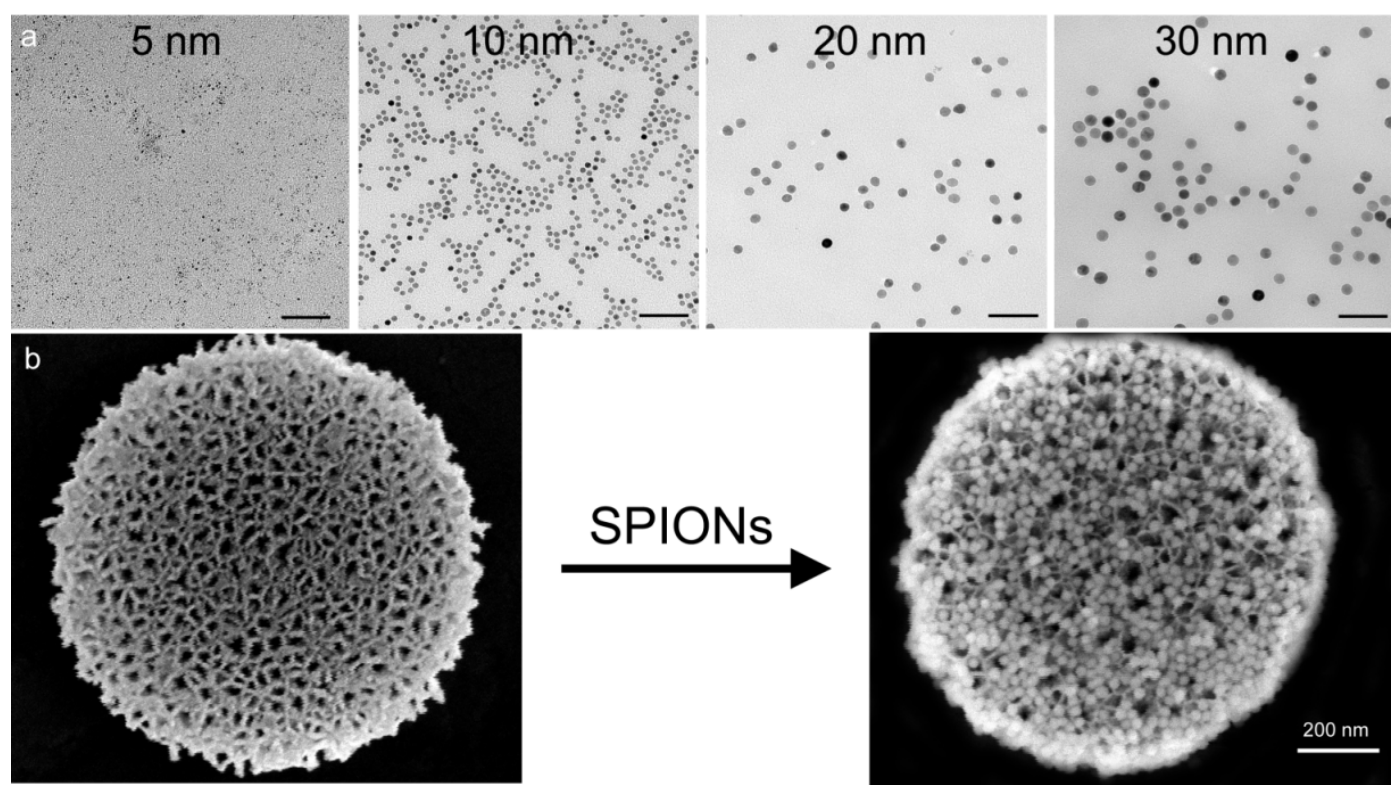

\subsection{SPION Magnetic Properties}

Differences in negative contrast in $\mathrm{T}_{2}$ and $\mathrm{T}_{2}{ }^{*}$-weighted images of SPIONs were visible in phantom preparations containing SPIONs of increasing core size (Figure 2a,b), despite the fact that the actual content of free iron remained constant. Devices used to create phantoms are shown pictorially in Figure 2c,d. SPIONs, suspended in 1\% agarose within NMR tubes, were placed in a 5 specimen holder which was then filled with relaxed water. As predicted by MAR theory, SPIONs showed a trend of increasing relaxivity with increasing core size using both $\mathrm{T}_{2}$ and $\mathrm{T}_{2}{ }^{*}$ imaging sequences (Table 1 and Figure 2e,f). This trend was demonstrated up to a core size of $20 \mathrm{~nm}$ for $\mathrm{T}_{2}$-weighted measurements. In 
contrast, a plateau was not reached for particles at or below $30 \mathrm{~nm}$ for $\mathrm{T}_{2}{ }^{*}$-weighted measurements (Figure 2e).

Table 1. Relaxivity values $r_{2}$ and $r_{2} *$ for each core size expressed as $\mathrm{mM}^{-1} \mathrm{~s}^{-1}(n=5$ data points except as indicated).

\begin{tabular}{ccccc}
\hline Core size $(\mathbf{n m})$ & \multicolumn{2}{c}{$\mathbf{T}_{\mathbf{2}}$ Relaxivity $\left(\mathbf{r}_{\mathbf{2}}\right)$} & \multicolumn{2}{c}{$\mathbf{T}_{2}{ }^{*}$ Relaxivity $\left(\mathbf{r}_{\mathbf{2}}{ }^{*}\right)$} \\
\hline 5 & 8.824 & $+/-0.50$ & 10.556 & $+/-0.90$ \\
10 & 79.56 & $+/-12.30$ & 128.69 & $+/-6.97$ \\
$20 *$ & 189.89 & $+/-18.64$ & 317.79 & $+/-15.58$ \\
$30 * *$ & 159.62 & $+/-4.09$ & 399.37 & $+/-20.28$ \\
\hline$* \mathrm{r}_{2}$ values calculated using $n=4$ data points; $* * \mathrm{r}_{2}$ values calculated using $n=3$ data points.
\end{tabular}

Figure 2. Impact of SPION core size on negative $\left(\mathrm{T}_{2}\right)$ contrast and proton relaxivity. (A) $\mathrm{T}_{2} \mathrm{MR}$ image, echo time $54 \mathrm{~ms}$, of an axial slice through agarose phantoms containing $5,10,20$, and $30 \mathrm{~nm}$ core size SPIONs with a pure 1\% agarose control (labeled Ag). All SPION phantoms contained an equivalent amount of iron oxide at a concentration of $0.05 \mathrm{mg} / \mathrm{mL}$; (B) $\mathrm{T}_{2} * \mathrm{MR}$ image, echo time $24.5 \mathrm{~ms}$, of an axial slice through the same phantoms as described in (A); (C) 3D model of apparatus used to image particle phantoms in MRI. Phantoms were suspended in ultrapure water and held away from the plastic ends of the sample holder to minimize artifacts created by abrupt changes in magnetic susceptibility between the phantoms and surrounding medium. The sample tubes and holder were constructed of polystyrene and polypropylene, respectively; (D) NMR sample tube with SPIONs suspended between 2 wax plugs and surrounded by DI water; (E) Comparison of $r_{2}$ and $r_{2} *$ values for 5, 10, 20, and $30 \mathrm{~nm}$ core size SPIONs with $95 \%$ CI displayed as error bars; (F) Plot of the relaxation rate $v s$. concentration of iron expressed in units of $\mathrm{mM}$ free iron. The slope of the relaxation rate $v s$. concentration curve represents the relaxivity, $\mathrm{r}_{2}$ and $\mathrm{r}_{2}{ }^{*}$, expressed as $1 /(\mathrm{mM} \times \mathrm{s})$.

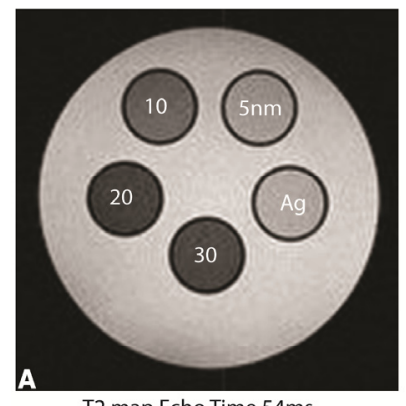

T2 map Echo Time 54ms

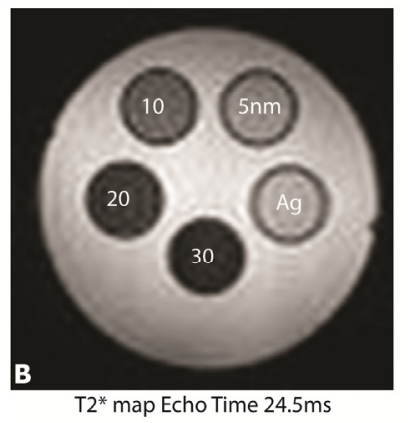

T2* map Echo Time $24.5 \mathrm{~ms}$

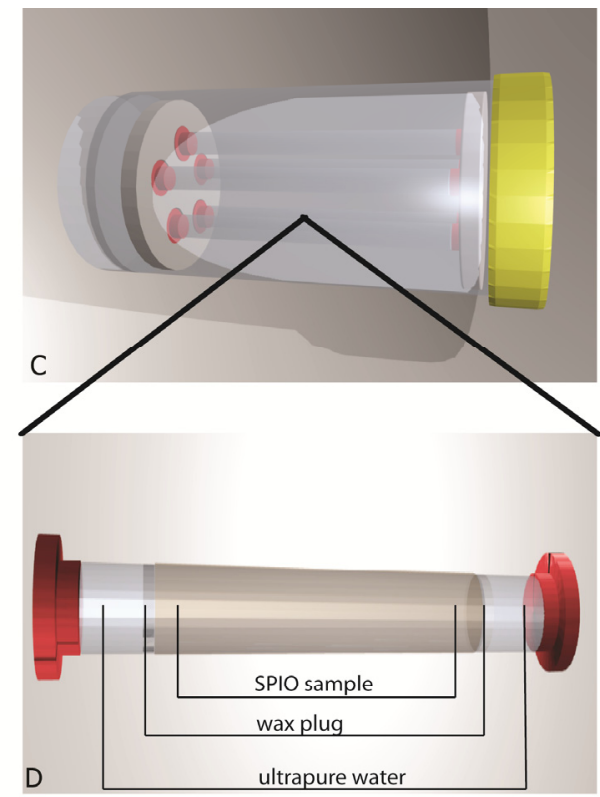

T2* Relaxivity 
Figure 2. Cont.
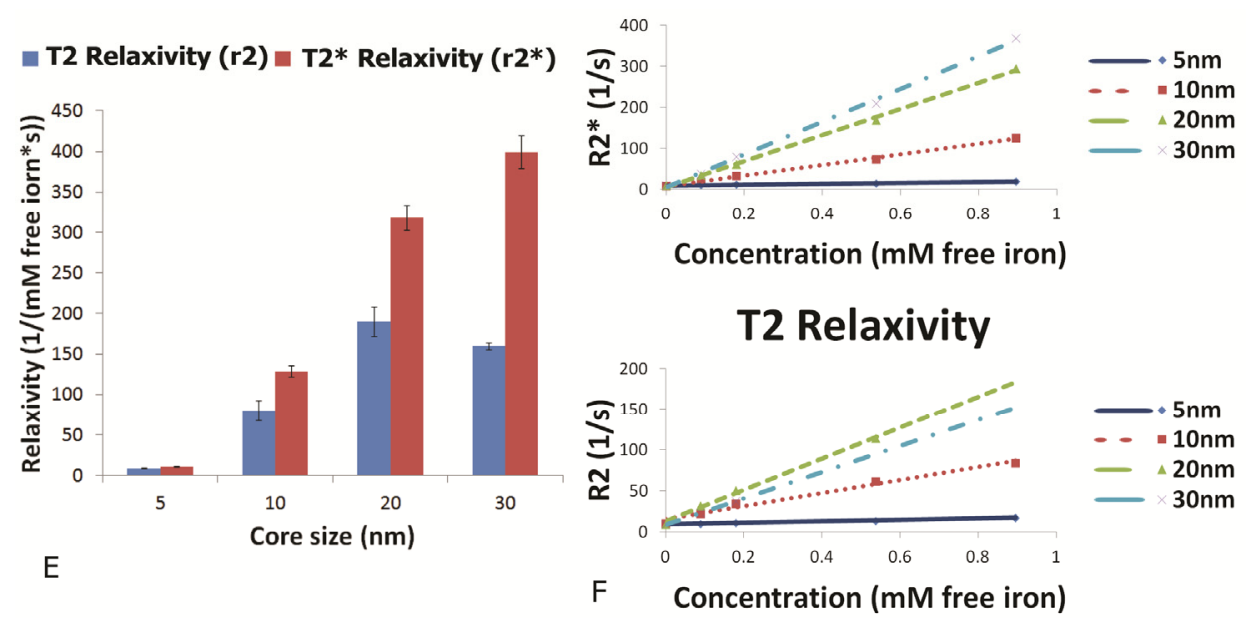

Figure 3. Influence of SPION encapsulation in the pores of $\mathrm{pSi}$ microparticles on MRI contrast enhancement and cellular uptake. (a) Computer simulated image showing SPIONs (red) loaded into a discoidal pSi microparticle; (b) $r_{2}$ and $r_{2} *$ relaxivity of free or encapsulated $30 \mathrm{~nm}$ SPIONs in agarose phantoms. Relaxivity was calculated using the slope of the relaxation rate $v s$. concentration. Error bars represent 95\% confidence intervals; (c) Bright field micrographs of J774 mouse macrophages following $24 \mathrm{~h}$ incubation with free (SPION) or pSi encapsulated SPIONs (pSi $+\mathrm{SPION}$ ), or unloaded pSi microparticles (pSi).

Cells were stained with Prussian blue to visualize localization of iron oxide.
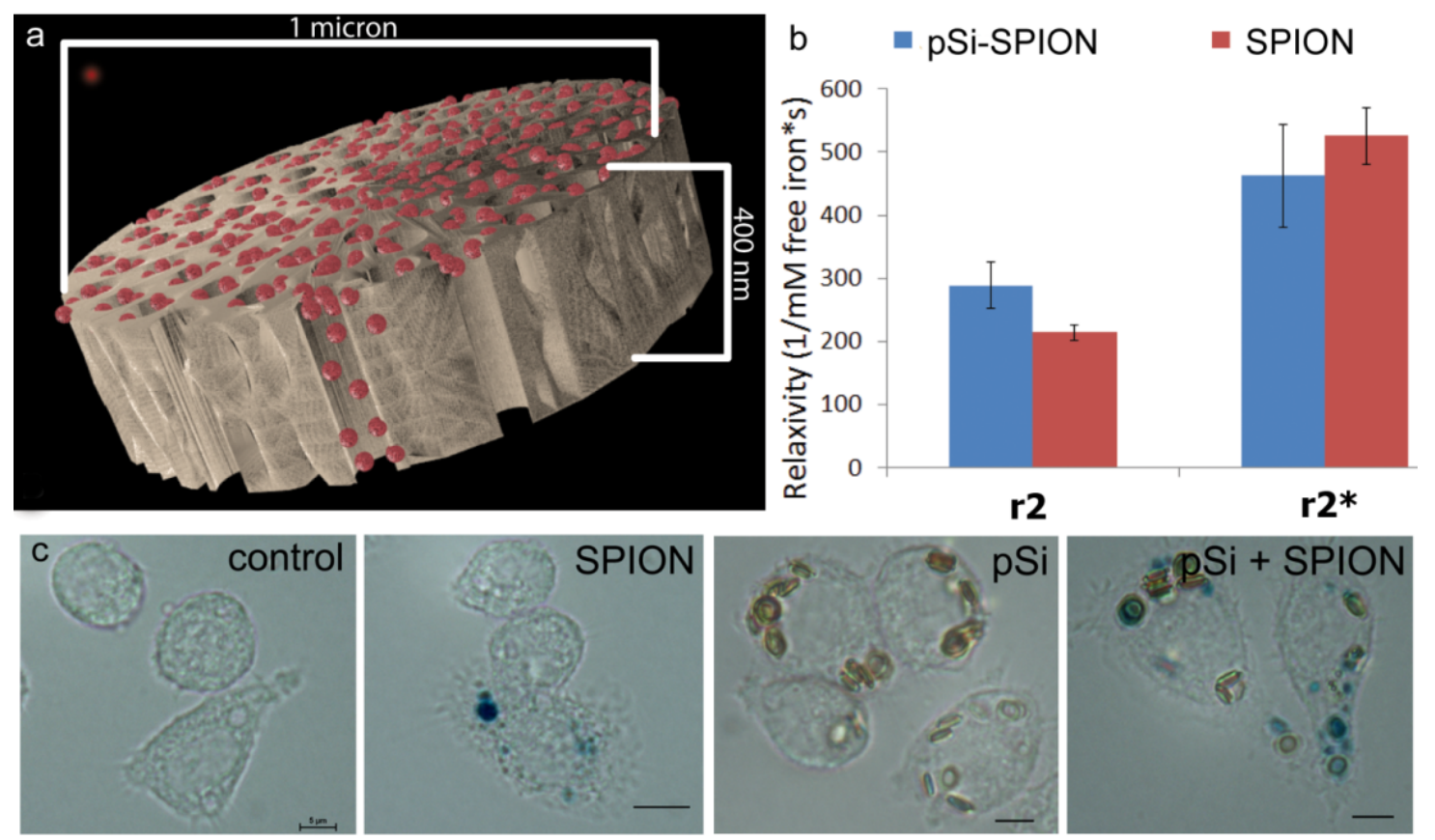

\subsection{Impact of pSi Encapsulation on SPION Magnetic Properties and Cellular Uptake}

Based on SDR thoery, it was hypothesized that SPION encapsulation in a pSi microparticle would increase $\mathrm{T}_{2} *$ relaxivity based on particle clustering within the silicion matrix. Loading of $30 \mathrm{~nm}$ SPIONs into discoidal pSi microparticles which was confirmed by SEM imaging (Figure 1b), is 
illustrated in Figure 3a. $T_{2}$ relaxivity $\left(\mathrm{r}_{2}\right)$ values for encapsulated and free SPIONs embedded in agarose phantoms were $288 \mathrm{mM}^{-1} \mathrm{~s}^{-1}$ (95\% CI 251-325) and $214 \mathrm{mM}^{-1} \mathrm{~s}^{-1}$ (95\% CI 202-225), respectively (Figure $3 \mathrm{~b}$ ). While this represents a statistically significant increase in $\mathrm{T}_{2}$ relaxivity with encapsulation, the magnitude of the increase is not predicted to be great enough to be clinically significant. $\mathrm{T}_{2}{ }^{*}$ relaxivity values for encapsulated and free SPIONs were statistically similar, at $462 \mathrm{mM}^{-1} \mathrm{~s}^{-1}$ (95\% CI 381-543) and $525 \mathrm{mM}^{-1} \mathrm{~s}^{-1}$ (95\% CI 480-570), respectively.

Macrophages are capable of internalizing both nano and micro particles [19,22,23]. In Figure 3c, we demonstrate uptake of free and pSi encapsulated SPIONs by J774 mouse macrophages following $24 \mathrm{~h}$ incubation at $37{ }^{\circ} \mathrm{C}$. Previously we reported that silicon microparticles remain entrapped in endolysosomes, while the fate of the secondary SPIONs is influenced by the surface properties of the nanoparticles. In Figure 3c, SPIONs, stained with Prussian blue, are shown both co-localized and distinct from the pSi microparticles.

\subsection{Accumulation of SPIONs in the Spleen}

Nanoparticles are being investigated as vaccine delivery vehicles for transporting immune modulators and antigens to APCs. In this study, we examined trafficking of SPIONs to lymphoid tissue based on enhanced negative contrast in the spleen. Mice, given intravenous injections of SPIONs $(100 \mu \mathrm{g} \mathrm{Fe})$, were sacrificed at 2 and $24 \mathrm{~h}$ post injection and axial $\mathrm{T}_{2}$-weighted images were acquired for spleen suspended in phantoms (Figure 4a). Nanoparticle accumulation was time-dependent, with signal intensity in the spleen being significantly lower for the animal sacrificed at $24 \mathrm{~h}$ compared to the control animal $(p<0.007)$ (Figure $4 b)$.

Figure 4. Time-dependent accumulation of intravenously injected SPIONs in the spleen of mice. (a) Spleen, recovered from mice at 2 and $24 \mathrm{~h}$ post intravenous injection with $20 \mathrm{~nm}$ SPIONs, were suspended in agarose phantoms and imaged using a 7T MR scanner. $\mathrm{T}_{2}$-weighted MR images are presented, along with the spleen from a control animal; (b) $\mathrm{T}_{2}$ values of the imaged spleen are displayed graphically $(* p<0.007$ compared to control).

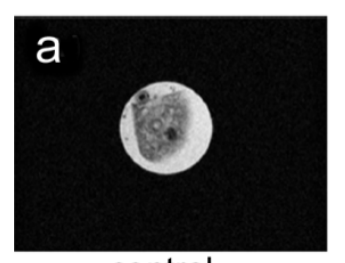

control

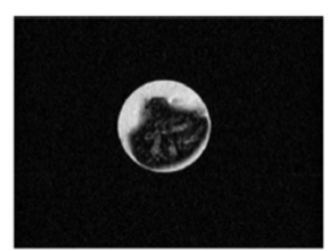

$2 \mathrm{~h}$

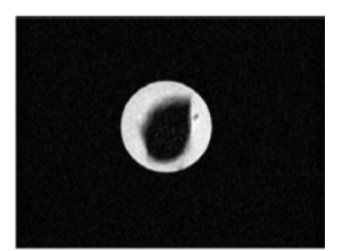

$24 \mathrm{~h}$

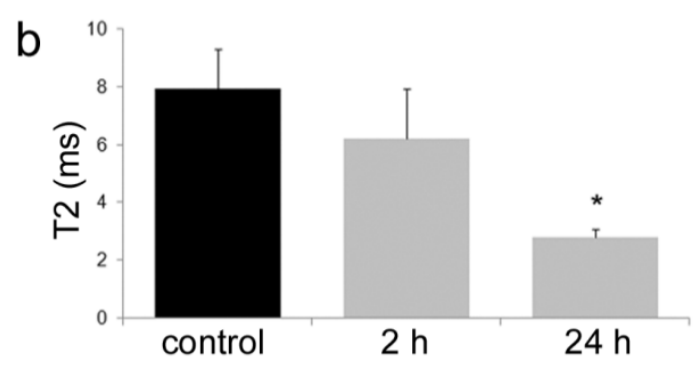




\subsection{Trafficking of Nanoparticles to Lymphoid Tissues}

To study the impact of particle presentation on trafficking of SPIONs to lymphoid tissue, axial $\mathrm{T}_{2}$-weighted images of nude mice following intravenous injections of free or pSi-encapsulated SPIONs $(100 \mu \mathrm{g} \mathrm{Fe})$ were acquired $24 \mathrm{~h}$ post injection (Figure 5a). Enhanced negative contrast due to SPION accumulation in the spleen was observed visually in mice injected with either free SPIONs or pSi-encapsulated SPIONs. Excised spleen was darker from SPION-treated compared to the control mice (Figure $5 \mathrm{~b}$ ). Average $\mathrm{T}_{2}$ contrast was significantly enhanced in the spleens of SPION-treated mice compared to control animals, with $\mathrm{T}_{2}$ values supporting greater accumulation of free SPIONs compared to hybrid particle SPIONs (Figure 5c). Co-localization of SPIONs and pSi microparticles in the spleen was confirmed by Prussian blue staining of histological specimens (Figure 5d).

Figure 5. Influence of SPION encapsulation in pSi microparticles on $T_{2}$ contrast in the spleen. (a) $\mathrm{T}_{2}$-weighted axial images of female nu/nu mice injected with either PBS (left), $30 \mathrm{~nm}$ SPIONs (100 $\mu \mathrm{g} \mathrm{Fe}$ ) (middle), or pSi-encapsulated $30 \mathrm{~nm}$ SPIONs (100 $\mu \mathrm{g}$ Fe; right) $24 \mathrm{~h}$ post injection. Spleens are indicated with white circles, with the corresponding gross tissues and weights shown below for each respective group (b). An internal SPION reference standard $(0.01 \mathrm{mg} / \mathrm{mL})$ (dark circle located at the top of each MRI image) was included in each image; (c) Measured in vivo $\mathrm{T}_{2}$ values for control, free (SPION) and encapsulated (pSi SPION) SPIONs. Data represents the mean of 5 ROIs in unique slices and the standard deviation ( $p<0.02 ; *$ compared to control; ** SPION vs. pSi SPION); (d) Histological specimens of dissected spleens isolated from mice treated with pSi-encapsulated SPIONs (24 h post injection) labeled with Prussian blue and Nuclear Fast Red.
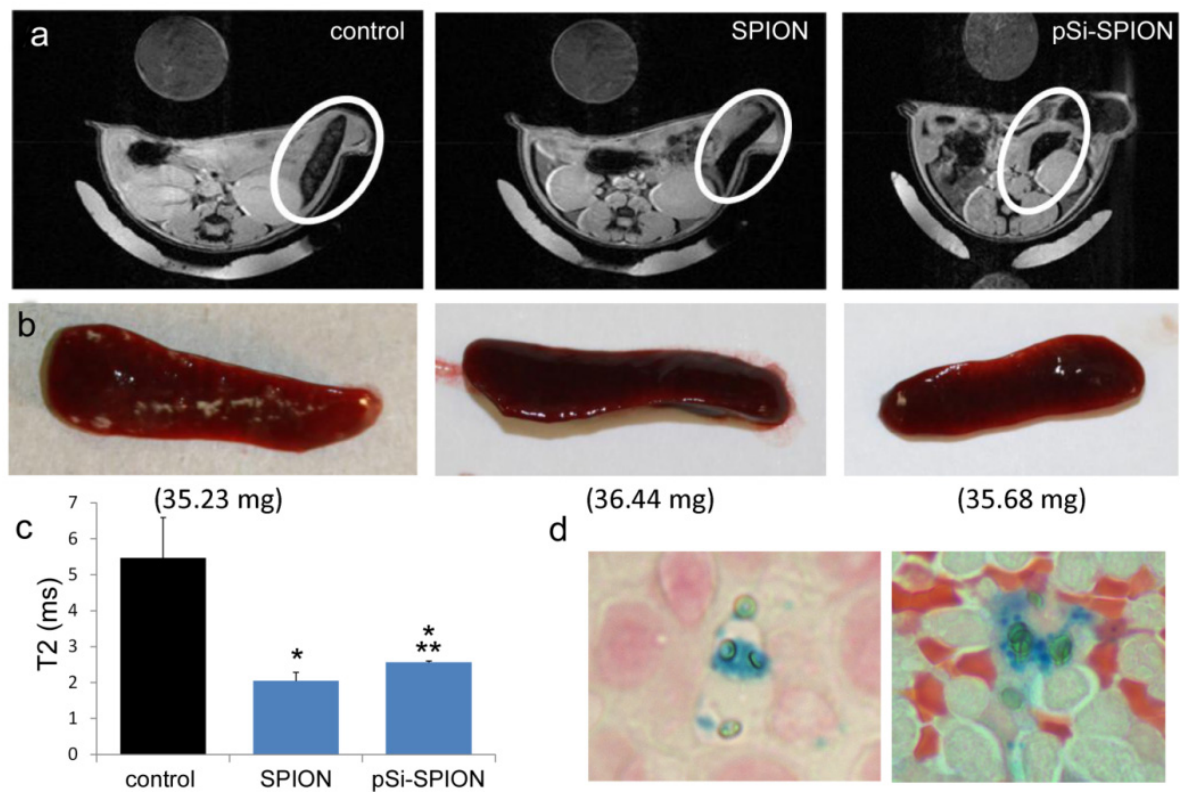

d

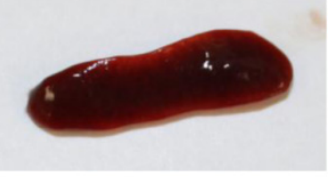

(35.68 mg)
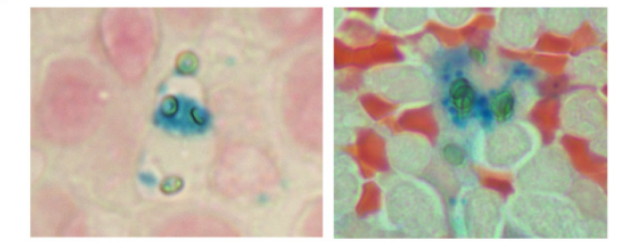
Figure 6. Hybrid particles as adjuvants for antigen presentation. (a) Computer simulated image showing SPIONs (red), ovalbumin peptide (OVA; green) and lipopolysaccharide (LPS) (blue) loaded into a pSi microparticle; (b) SEM images showing control and pSi microparticle-treated bone marrow-derived dendritic cells (BMDC) (30 min; bars 3 (left) and $2 \mu \mathrm{m}$ (right); $10-13 \mathrm{k} \mathrm{mag}$ ). High magnification images show a group of microparticles on the cell surface (bottom left, bar $500 \mathrm{~nm} ; 50 \mathrm{k} \mathrm{mag}$ ) and two microparticles engulfed in BMDC membrane folds during early uptake (bottom right; bar $1 \mu \mathrm{m} ; 40 \mathrm{k} \mathrm{mag}$ ); (c) SEM image showing particle adjuvant-induced association of a $\mathrm{T}$ cell with the stimulated BMDC; (d) TEM image showing a BMDC following treatment with LPS-pSi microparticles $(3 \mathrm{~h}$; bar $2 \mu \mathrm{m}$ ). The boxed region is shown at higher magnification in the lower left image, showing microparticles surrounded by cytoplasmic constituents. The bottom right image shows a $\mathrm{T}$ cell bound to a BMDC following treatment with adjuvant particles; (e) Flow cytometry dot blots showing the percent of interferon- $\gamma(\mathrm{IFN}-\gamma)$ positive OT-1 CD8 ${ }^{+} \mathrm{T}$ cells following $4 \mathrm{~h}$ treatment with particle-stimulated $(24 \mathrm{~h}) \mathrm{C} 57 \mathrm{BL} / 6 \mathrm{BMDC}$ (reproduced courtesy of Meraz et al. [24]); (f) C57BL/6 BMDC were incubated with various formulations of the hybrid particle vaccine then introduced to OT-1 T cells for $4 \mathrm{~h}$, followed by analysis for intracellular IFN- $\gamma$ production by flow cytometry $(n=3)$. Controls included free LPS, unloaded pSi microparticles, and LPS-pSi microparticles, either empty (control) or loaded with OVA peptide, in the absence or presence of $20 \mathrm{~nm}$ SPIONS (abbreviated OVA and IO OVA) (*p<0.0007).

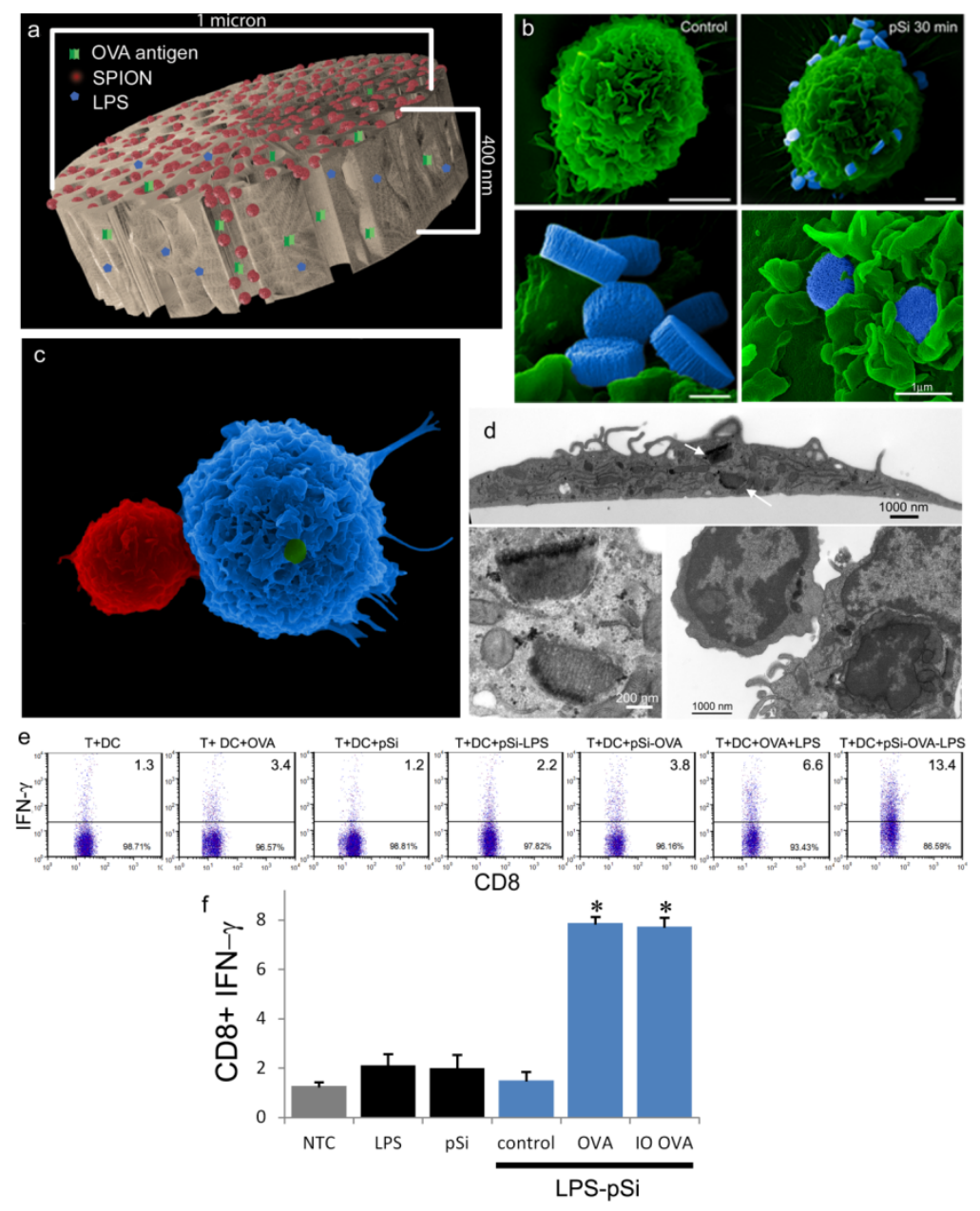




\subsection{Hybrid Particles as Vaccines Platforms}

Using particles as carriers for adjuvants and antigens simultaneously stimulates APCs and leads to internalization of antigen, with sustained release of the antigen potentially expanding the duration of antigen presentation. We previously demonstrated that multivalent presentation of toll-like receptor (TLR) ligands on the surface of carrier silicon microparticles activates DC to a greater extent than free ligand, leading to enhanced DC uptake, and increased migration of DC to the draining lymph node [24]. In this study, we have added a model antigen (OVA) and secondary nanoparticles (i.e., SPIONs) to the complex to direct the immune response and to enable tracking of the vaccine (Figure 6a). As stated, BMDC internalize TLR ligand bound pSi microparticles. In Figure 6b, a control BMDC is shown pseudo-colored in green. To the right, a second BMDC is shown with blue-pseudo-colored pSi microparticles bound to the cell membrane. The boxed region in the image is shown at higher magnification in the bottom row of images to highlight microparticle orientation and early stages of phagocytosis. Membrane veils can be seen wrapping around the microparticles in the bottom right image of Figure $6 b$.

To study antigen presentation by microparticle (LPS-OVA-pSi)-treated C57BL/6 BMDC to OT-1 T cells, we first used SEM to demonstrate particle-induced cellular interactions (Figure 6c). The large $\mathrm{DC}$ is seen bound to the smaller $\mathrm{T}$ cell. Confirmation of microparticle internalization within BMDC was achieved using TEM imaging. The arrows in Figure 6d indicate microparticles within the cell, with the internalized particles (boxed region) shown in the higher magnification image in the lower left image. A close-up view of T cell-DC binding is shown in the lower right image. Following particle activation of BMDC and incubation with OT-1 T cells, intracellular IFN- $\gamma$ production was evaluated in $\mathrm{CD}^{+} \mathrm{T}$ cells by flow cytometry. Figure 6e, adapted from Meraz et al. [24], shows that LPS enhances OVA induced IFN- $\gamma$ production by T cells, and that presentation of LPS by particles further increases $\mathrm{T}$ cell activation. In a novel experiment (Figure 6f), incubation of BMDC with LPS-pSi microparticles loaded with OVA peptide, in the presence and absence of SPIONs, stimulated IFN- $\gamma$ production by $\mathrm{CD} 8^{+} \mathrm{T}$ cells.

\section{Discussion}

Previously, we demonstrated that loading of SPIONs into pSi microparticles creates hybrid particles with magnetic properties, with increasing payloads of SPIONs inducing greater negative contrast in MR images [19]. During the loading process, increases in the concentration of SPIONs introduced to dry pSi microparticles increases nanoparticle loading in the silicon pores, with a plateau reached at concentrations above $1 \mathrm{mg} / \mathrm{mL}$ [19] Theoretically, the pore volume of each $1000 \times 400 \mathrm{~nm} \mathrm{pSi}$ microparticle is about $0.2 \mu \mathrm{m}^{3}$, permitting loading of up to $3.8 \times 10^{5} 10 \mathrm{~nm}$ nanoparticles. Empirically, we previously demonstrated loading of $0.3 \mathrm{pg}$ of $10 \mathrm{~nm}$ SPIONs per pSi microparticle, corresponding to approximately $1 \times 10^{5}$ SPIONs [25].

This manuscript expands on previous work by showing the impact of SPION size and encapsulation in the pores of a silicon microparticle on negative contrast enhancement. As stated previously, relaxation effects of SPIONs are governed by their magnetic properties which are determined by particle size, shape and morphology. As reported by others, we demonstrated that increasing core sizes 
generates superior relaxivities [26]. At the level of external magnetic field strength of most clinical scanners (1.5-3 Tesla), the induced magnetization of SPION contrast agents is very close to the asymptotic upper limit, referred to as the induced magnetization at saturation. As the diameter of SPIONs is increased, the induced magnetization at saturation also increases [27], causing increases in $\mathrm{T}_{2}$ and $\mathrm{T}_{2}{ }^{*}$ relaxivity [28]. Plotting relaxation rates $\left(\mathrm{T}_{2}, \mathrm{~T}_{2}{ }^{*}\right)$ against concentration ( $\mathrm{mM}$ free iron) generates slopes which yield the concentration-independent relaxivities $\left(\mathrm{r}_{2}\right.$ and $\left.\mathrm{r}_{2}{ }^{*}\right)$. In this study, using a 7 Tesla scanner, we demonstrate that SPION relaxivities increase with particle diameters ranging from 5 to $30 \mathrm{~nm}$, with iron saturation effects becoming apparent for $r_{2}$ values for particles $20 \mathrm{~nm}$ and higher, and $\mathrm{r}_{2} *$ showing a further increase as the core size increases from 20 to $30 \mathrm{~nm}$.

Accumulation of ultrasmall SPIONs in the phagosomes of macrophages has been shown to enhance decreases in the signal intensity of $T_{2}{ }^{*}$-weighted images due to shortening of $T_{2}$ and $T_{2}{ }^{*}$, with tissue clustering leading to additional $\mathrm{T}_{2}{ }^{*}$ shortening effects [29]. Similarly, spatial confinement of SPIONs in larger nanoparticles, such as micelles, has been shown to produce strong field gradients leading to increased transverse relaxivities [30,31]. Kinsella et al. [32] reported that encapsulation of $9 \mathrm{~nm} \mathrm{Fe}_{3} \mathrm{O}_{4}$ in $16 \mathrm{~nm}$ silicon pores led to an increase in magnetic strength causing an increase in transverse relaxivity. In this study, encapsulation of $30 \mathrm{~nm}$ SPIONs within a pSi matrix (50 nm pores) caused a slight decrease $(p<0.05)$ in $\mathrm{T}_{2}$ transverse relaxation, but no significant impact on $\mathrm{T}_{2}{ }^{*}$ values. There was no increase in the ratio of $\mathrm{R}_{2} *$ to $\mathrm{R}_{2}$ with compartmentalization of SPIONs in $\mathrm{pSi}$, as predicted by SDR theory. In contrast to previous work by our group [33] that showed large alterations in $\mathrm{T}_{1}$ contrast with encapsulation of gadolinium within pSi microparticles, the small enhancement in $\mathrm{T}_{2}$ relaxivity due to encapsulation of SPIONs in pSi microparticles is not likely to add significant clinical benefit on its own. However, benefits of using hybrid particle complexes, as opposed to free SPIONs, are due to incorporation of additional biologically active agents, such as immune modulators and antigens, achieving delivery of both imaging and therapeutic agents to the same target cells.

As previously demonstrated by others, free SPIONs accumulate predominately in the liver and spleen following intravenous administration [34], with size and surface modification of the nanoparticles impacting biodistribution [35]. Time-dependent accumulation of SPIONs in the spleen with time (Figure 4) was confirmed, with greater levels of SPIONs detected at $24 \mathrm{~h}$ compared to $2 \mathrm{~h}$ by MRI. Based on higher accumulation at the later time point, $24 \mathrm{~h}$ was used for in vivo MR imaging studies designed to compare accumulation (i.e., detection) of free verses pSi encapsulated SPIONs. Detection of free SPION accumulation in the spleen was slightly superior to pSi-encapsulated SPIONs following intravascular injection. Future work will examine particle accumulation in the draining lymph nodes following subcutaneous injection to explore the impact of mode of transportation (i.e., cell-based transport for larger particles verses exit from capillaries and trafficking through the lymphatic system for smaller particles [17]) on particle accumulation in lymphatic tissue. In addition, we previously demonstrated that particle surface charge alters accumulation of microparticles in the spleen following intravenous administration, with cationic microparticles accumulating preferentially over anionic microparticles [21]. Since both particle charge and macromolecule binding (e.g., opsonization or ligand conjugation) to the particle surface influence biodistribution, future studies will also examine the impact of loading microparticles with antigens and immune modulators on trafficking of vaccine components to lymphatic tissue. 
As demonstrated previously, we show abundant adhesion and uptake of pSi microparticles by BMDC. Loading of antigen and immune modulators (i.e., LPS) stimulates antigen driven interactions between OT-1 T cells and particle-treated BMDC, with enhanced production of IFN- $\gamma$ in activated $\mathrm{CD}^{+} \mathrm{T}$ cells. Incorporation of SPIONs into the particle complex did not alter stimulation of $\mathrm{T}$ cell immunity, supporting the use of the hybrid particles for the development of immunotherapeutics.

\section{Conclusions}

This study supports well-established theories of size-dependent enhanced transverse relaxivity of surrounding water protons by SPIONs. While particle presentation did not have a major impact on contrast enhancement, a hybrid particle system did permit presentation of a diverse payload for a theranostic approach to vaccination. Our hybrid particle vaccine presents contrast agents and antigens in combination with pattern-associated molecular pattern molecules for tracking and stimulation of targeted immune responses. Preliminary data supports antigen presentation by particle-treated DC and stimulation of cellular immune responses. Future work will test the efficacy of the hybrid particle complex for generation of in vivo immune responses.

\section{Acknowledgments}

We acknowledge use of the Houston Methodist Research Institute (HMRI) Translational Imaging, Flow Cytometry, and Scanning Electron Microscopy Cores. We thank the HMRI silicon fabrication team for making pSi microparticles, Jianhua Gu for assistance with SEM imaging, and James P. Barrish, Technical Specialist in the Department of Pathology Electron Microscopy Facility at Texas Children's Hospital for TEM sample preparation and imaging. Funding was provided by the National Institute of Health Grant U54 CA151668 and the Department of Defense Grant DODW81XWH-07-1-0596.

\section{Author Contributions}

R.E.S. and C.M.L. designed all experiments and wrote the paper. C.L. and J.D. imaged SPION accumulation in the spleen by MRI. I.M.M. performed ex vivo experiments with splenic $\mathrm{T}$ cells and BMDC. X.L. designed and made pSi microparticles.

\section{Conflicts of Interest}

Xuewu Liu has patents for porous silicon fabrication and ownership interest in Leonardo Biosystems. Rita Serda and Ismail Meraz have a patent pertaining to the use of porous silicon for adjuvant and vaccine purposes.

\section{References}

1. Petrilli, V.; Dostert, C.; Muruve, D.A.; Tschopp, J. The inflammasome: A danger sensing complex triggering innate immunity. Curr. Opin. Immunol. 2007, 19, 615-622.

2. Akira, S.; Takeda, K.; Kaisho, T. Toll-like receptors: Critical proteins linking innate and acquired immunity. Nat. Immunol. 2001, 2, 675-680. 
3. Mitchell, D.G. Hepatic imaging: Techniques and unique applications of magnetic resonance imaging. Magn. Reson. Q. 1993, 9, 84-112.

4. Lee, D.H. Mechanisms of contrast enhancement in magnetic resonance imaging. Can. Assoc. Radiol. J. 1991, 42, 6-12.

5. Kirsch, J.E. Basic principles of magnetic resonance contrast agents. Top. Magn. Reson. Imag. 1991, 3, 1-18.

6. Bjornerud, A.; Johansson, L. The utility of superparamagnetic contrast agents in mri: Theoretical consideration and applications in the cardiovascular system. NMR Biomed. 2004, 17, 465-477.

7. Gossuin, Y.; Gillis, P.; Hocq, A.; Vuong, Q.L.; Roch, A. Magnetic resonance relaxation properties of superparamagnetic particles. Wiley Interdiscip. Rev. Nanomed. Nanobiotechnol. 2009, 1, 299-310.

8. Tromsdorf, U.I.; Bigall, N.C.; Kaul, M.G.; Bruns, O.T.; Nikolic, M.S.; Mollwitz, B.; Sperling, R.A.; Reimer, R.; Hohenberg, H.; Parak, W.J.; et al. Size and surface effects on the mri relaxivity of manganese ferrite nanoparticle contrast agents. Nano Lett. 2007, 7, 2422-2427.

9. Tanimoto, A.; Oshio, K.; Suematsu, M.; Pouliquen, D.; Stark, D.D. Relaxation effects of clustered particles. J. Magn. Reson. Imaging 2001, 14, 72-77.

10. Lee, J.H.; Huh, Y.M.; Jun, Y.W.; Seo, J.W.; Jang, J.T.; Song, H.T.; Kim, S.; Cho, E.J.; Yoon, H.G.; Suh, J.S.; et al. Artificially engineered magnetic nanoparticles for ultra-sensitive molecular imaging. Nat. Med. 2007, 13, 95-99.

11. Gillis, P.; Moiny, F.; Brooks, R.A. On $\mathrm{T}_{2}$-shortening by strongly magnetized spheres: A partial refocusing model. Magn. Reson. Med. 2002, 47, 257-263.

12. Gillis, P.; Roch, A.; Brooks, R.A. Corrected equations for susceptibility-induced $\mathrm{T}_{2}$-shortening. J. Magn. Reson. 1999, 137, 402-407.

13. Lundquist, C.M.; Loo, C.H.; Mack, A.; Gu, J.; Bankson, J.A.; Serda, R.E. Porous silicon-superparamagnetic iron oxide complexes and impact on negative contrast enhancement in MRI. In Proceedings of the ASME 2013 2nd Global Congress on NanoEngineering for Medicine and Biology, Boston, MA, USA, 4-6 February 2013; doi:10.1115/NEMB2013-93065.

14. Muro, S.; Garnacho, C.; Champion, J.A.; Leferovich, J.; Gajewski, C.; Schuchman, E.H.; Mitragotri, S.; Muzykantov, V.R. Control of endothelial targeting and intracellular delivery of therapeutic enzymes by modulating the size and shape of icam-1-targeted carriers. Mol. Ther. 2008, 16, 1450-1458.

15. Champion, J.A.; Mitragotri, S. Role of target geometry in phagocytosis. Proc. Natl. Acad. Sci. USA 2006, 103, 4930-4934.

16. Serda, R.E.; Godin, B.; Blanco, E.; Chiappini, C.; Ferrari, M. Multi-stage delivery nano-particle systems for therapeutic applications. Biochim. Biophys. Acta 2010, 1810, 317-329.

17. Manolova, V.; Flace, A.; Bauer, M.; Schwarz, K.; Saudan, P.; Bachmann, M.F. Nanoparticles target distinct dendritic cell populations according to their size. Eur. J. Immunol. 2008, 38, 1404-1413.

18. Serda, R.E.; Gu, J.; Bhavane, R.C.; Liu, X.; Chiappini, C.; Decuzzi, P.; Ferrari, M. The association of silicon microparticles with endothelial cells in drug delivery to the vasculature. Biomaterials 2009, 30, 2440-2448. 
19. Serda, R.E.; Mack, A.; Pulikkathara, M.; Zaske, A.M.; Chiappini, C.; Fakhoury, J.; Webb, D.; Godin, B.; Conyers, J.L.; Liu, X.W.; et al. Cellular association and assembly of a multistage delivery system. Small 2010, 6, 1329-1340.

20. FACSDIVA Software, V6.0; BD Biosciences: San Jose, CA, USA, 2007.

21. Serda, R.E.; Blanco, E.; Mack, A.; Stafford, S.J.; Amra, S.; Li, Q.; van de Ven, A.; Tanaka, T.; Torchilin, V.P.; Wiktorowicz, J.E.; et al. Proteomic analysis of serum opsonins impacting biodistribution and cellular association of porous silicon microparticles. Mol. Imaging 2011, 10, 43-55.

22. Ferrati, S.; Mack, A.; Chiappini, C.; Liu, X.; Bean, A.J.; Ferrari, M.; Serda, R.E. Intracellular trafficking of silicon particles and logic-embedded vectors. Nanoscale 2010, 2, 1512-1520.

23. Serda, R.E.; Mack, A.; van de Ven, A.L.; Ferrati, S.; Dunner, K., Jr.; Godin, B.; Chiappini, C.; Landry, M.; Brousseau, L.; Liu, X.; et al. Logic-embedded vectors for intracellular partitioning, endosomal escape, and exocytosis of nanoparticles. Small 2010, 6, 2691-2700.

24. Meraz, I.M.; Melendez, B.; Gu, J.; Wong, S.T.; Liu, X.; Andersson, H.A.; Serda, R.E. Activation of the inflammasome and enhanced migration of microparticle-stimulated dendritic cells to the draining lymph node. Mol. Pharm. 2012, 9, 2049-2062.

25. Godin, B.; Tasciotti, E.; Liu, X.; Serda, R.E.; Ferrari, M. Multistage nanovectors: From concept to novel imaging contrast agents and therapeutics. Accounts Chem. Res. 2011, 44, 979-989.

26. Smolensky, E.D.; Park, H.Y.; Zhou, Y.; Rolla, G.A.; Marjanska, M.; Botta, M.; Pierre, V.C. Scaling laws at the nano size: The effect of particle size and shape on the magnetism and relaxivity of iron oxide nanoparticle contrast agents. J. Mater. Chem. B 2013, 1, 2818-2828.

27. Dispersion of Fine Silica Particles Using Alkoxysilane and Industrialization. In Nanoparticle Technology Handbook, 2nd ed.; Hosokawa, M., Nogi, K., Naito, M., Yokoyama, T., Eds.; Elsevier: Amsterdam, The Netherlands, 2007; Chapter 1, p. 44.

28. Kuhlpeter, R.; Dahnke, H.; Matuszewski, L.; Persigehl, T.; von Wallbrunn, A.; Allkemper, T.; Heindel, W.L.; Schaeffter, T.; Bremer, C. $\mathrm{R}_{2}$ and $\mathrm{R}_{2}{ }^{*}$ mapping for sensing cell-bound superparamagnetic nanoparticles: In vitro and murine in vivo testing. Radiology 2007, 245, 449-457.

29. Kooi, M.E.; Cappendijk, V.C.; Cleutjens, K.B.; Kessels, A.G.; Kitslaar, P.J.; Borgers, M.; Frederik, P.M.; Daemen, M.J.; van Engelshoven, J.M. Accumulation of ultrasmall superparamagnetic particles of iron oxide in human atherosclerotic plaques can be detected by in vivo magnetic resonance imaging. Circulation 2003, 107, 2453-2458.

30. Lee, S.J.; Muthiah, M.; Lee, H.J.; Lee, H.J.; Moon, M.J.; Che, H.L.; Heo, S.U.; Lee, H.C.; Jeong, Y.Y.; Park, I.K. Synthesis and characterization of magnetic nanoparticle-embedded multi-functional polymeric micelles for mri-guided gene delivery. Macromol. Res. 2012, 20, 188-196.

31. Sawant, R.M.; Sawant, R.R.; Gultepe, E.; Nagesha, D.; Paphadjopoulos-Sternberg, B.P.; Sridhar, S.; Torchilin, V.P. Nanosized cancer cell-targeted polymeric immunomicelles loaded with superparamagnetic iron oxide nanoparticles. J. Nanopart. Res. 2009, 11, 1777-1785.

32. Kinsella, J.M.; Ananda, S.; Andrew, J.S.; Grondek, J.F.; Chien, M.P.; Scadeng, M.; Gianneschi, N.C.; Ruoslahti, E.; Sailor, M.J. Enhanced magnetic resonance contrast of feo nanoparticles trapped in a porous silicon nanoparticle host. Adv. Mater. 2011, 23, H248-H253. 
33. Ananta, J.S.; Godin, B.; Sethi, R.; Moriggi, L.; Liu, X.; Serda, R.E.; Krishnamurthy, R.; Muthupillai, R.; Bolskar, R.D.; Helm, L.; et al. Geometrical confinement of gadolinium-based contrast agents in nanoporous particles enhances $\mathrm{T}_{1}$ contrast. Nat. Nanotechnol. 2010, 5, 815-821.

34. Wang, J.; Chen, Y.; Chen, B.; Ding, J.; Xia, G.; Gao, C.; Cheng, J.; Jin, N.; Zhou, Y.; Li, X.; et al. Pharmacokinetic parameters and tissue distribution of magnetic $\mathrm{Fe}_{3} \mathrm{O}_{4}$ nanoparticles in mice. Int. J. Nanomed. 2010, 5, 861-866.

35. Thorek, D.L.; Tsourkas, A. Size, charge and concentration dependent uptake of iron oxide particles by non-phagocytic cells. Biomaterials 2008, 29, 3583-3590.

(C) 2014 by the authors; licensee MDPI, Basel, Switzerland. This article is an open access article distributed under the terms and conditions of the Creative Commons Attribution license (http://creativecommons.org/licenses/by/3.0/). 